UCRL-ID-123779

\title{
XUV Radiography Measurements of Direct Drive Imprint in Thin Aluminum Foils Using a GE X-ray Laser on Valcun
}

\author{
D. H. Kalantar, A. Demir, M. H. Key, N. S. Kim, \\ C. L. S. Lewis, J. Lin, D. Neely, A. McPhee, \\ B. A. Remington, R. Smith, G. J. Tallents, \\ J. S. Wark, J. Warwick, S. V. Weber, \\ E. Wolfrum, and J. Zhang
}

RECEIVED

JUH 059996

OSTI

March 29, 1996

$\therefore$ This is an informal report intended primarily for internal or limited external distribution. The opinions and conclusions stated are those of the author and may or may not be those of the Laboratory.

- Work performed under the auspices of the U.S. Department of Energy by the

Lawrence Livermore National Laboratory under Contract W-7405-Eng-48.

\section{DISCLAIMER}

This report was prepared as an account of work sponsored by an agency of the United States Government. Neither the United States Government nor any agency thereof, nor any of their employees, makes any warranty, express or implied, or assumes any legal liability or responsibility for the accuracy, completeness, or usefulness of any information, apparatus, product, or process disclosed, or represents that its use would not infringe privately owned rights. Reference herein to any specific commercial product, process, or service by trade name, trademark, manufacturer, or otherwise does not necessarily constitute or imply its endorsement, recommendation, or favoring by the United States Government or any agency thereof. The views and opinions of authors expressed herein do not necessarily state or reflect those of the United States Government or any agency thereof. 


\section{DISCLAIMER}

This document was prepared as an account of work sponsored by an agency of the United States Government. Neither the United States Government nor the University of California nor any of their employees, makes any warranty, express or implied, or assumes any legal liability or responsibility for the accuracy, completeness, or usefulness of any information, apparatus, product, or process disclosed, or represents that its use would not infringe privately owned rights. Reference herein to any specific commercial product, process, or service by trade name, trademark, manufacturer, or otherwise, does not necessarily constitute or imply its endorsement, recommendation, or favoring by the United States Government or the University of California. The views and opinions of authors expressed herein do not necessarily state or reflect those of the United States Government or the University of California, and shall not be used for advertising or product endorsement purposes.

This report has been reproduced directly from the best available copy.

Available to DOE and DOE contractors from the Office of Scientific and Technical Information

P.O. Box 62, Oak Ridge, TN 37831

Prices available from (615) 576-8401, FTS 626-8401

Available to the public from the

National Technical Information Service

U.S. Department of Commerce

5285 Port Royal Rd.

Springfield, VA 22161 


\title{
XUV RADIOGRAPHY MEASUREMENTS OF DIRECT DRIVE IMPRINT IN THIN ALUMINUM FOILS USING A GE X-RAY LASER ON VULCAN *
}

\author{
"Lawrence Livermore National Laboratory, USA \\ ${ }^{2}$ Essex University, UK \\ ${ }^{3)}$ Rutherford Appleton Laboratory, UK \\ ${ }^{4}$ Queen's Univeristy, UK \\ "Oxford University, UK
}

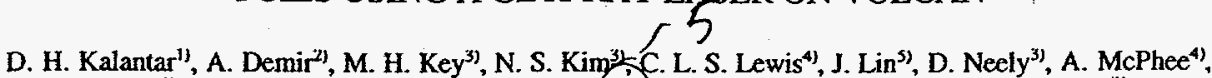

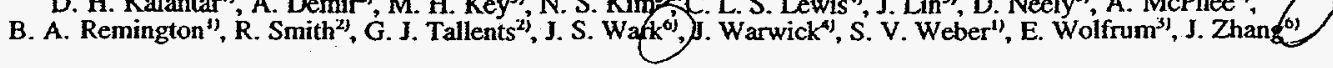

\section{INTRODUCTION}

One key aspect for high gain direct drive inertial confinement fusion is the imprint of perturbations in the outer surface of a capsule due to nonuniformities in the direct laser illumination of the capsule. Direct drive implosions are achieved by uniformly irradiating the outside surface of a hollow spherical capsule that contains a layer of fusionable D-T on its inner surface. The intensity of laser irradiation is down with a low intensity 'foot' at $10^{13} \mathrm{~W} / \mathrm{cm}^{2}$ for several nanoseconds before it builds up to more tha $10^{15} \mathrm{~W} / \mathrm{cm}^{2}$ during the main drive portion of the pulse. Laser ablation of the capsule surface produces a high pressure that accelerates the capsuel shell radially inward in a spherical implosion. During this acceleration, peritbations duc to surface roughness and due to imprint from spatial non-uniformitics in the laser irradiation undergo Rayleigh-Taylor growth, potentially severely degrading performance.

Our interest is in studying the imprint process and subsequent Rayleigh-Taylor growth of perturbations in a foil target that is irradiated by a low intensity laser speckle pattern. Previous experiments have been done to study laser imprint with an $x$-ray laser backlighter at the Nova laser using $0.35 \mu \mathrm{m}$ laser irradiation of al $3 \mu \mathrm{m} \mathrm{Si}$ foil 1.2 .3 . In these cxperiments we irradiated a $2 \mu \mathrm{m}$ thick Al foil with $0.53 \mu \mathrm{m}$ laser light at $2.8 \times 10^{12} \mathrm{~W} / \mathrm{cm}^{2}$ using the Vulcan laser. We used a Ge $x$-ray laser ${ }^{4}$ as an XUV backlighter to measure the modulation in optical depth of the foil on a CCD during the initial imprint phase and after Rayleigh-Tayler growth with different laser smoothing schemes.

We used a single Vulcan laser beam with a static random phase plate speckle pattern, smoothing by spectral dispersion, and sinoothing by ISI. We compared the results with results from a multiple beam overlap of static speckle patterns and SSD smoothed speckle patterns. We also measured the growth of a single wavelength modulation that was imprinted by a single mode optical intensity modulation onto the target. We used AI foil targets since Al has the lowest opacity for the Ne-like Ge $\mathrm{x}$-ray laser wavelength of $19.6 \mathrm{~nm}$. The Al is still highly attenuating, which limits the experiment to thin foils. It also means, however, that the technique is sensitive to small modulations in the thickness of the foil. At $19.6 \mathrm{~nm}$, the product of opacity time density for Al is $2.24 \mu \mathrm{m}^{-1}$. With this high an opacity, a thickness variation of only $50 \mathrm{~nm}$ results in a $10 \%$ change in signal intensity.

\section{EXPERIMENT}

We used six beams of the Vulcan laser 10 generate a Ge $x$-ray laser. Three of the six beams of $1.06 \mu \mathrm{m}$ laser light were focused with an overlapping line focus onto each of two $100 \mu \mathrm{m}$ wide strips of Ge deposited on glass slides. For these experiments we used two $18 \mathrm{~mm}$ targets that had a separation of $200 \mu \mathrm{m}$, as illustrated in Figure 1. We used 100 ps pulses with a $10 \%$ prepulse $2 \mathrm{~ns}$ before the main pulse. Under these conditions, the $x$ ray laser beam had a divergence of about $30 \mathrm{mrad}$ in the plane of the $x$-ray laser target surface, and 10 mrad normal to the plane.

We placed a thin $(2 \mu \mathrm{m})$ Al foil about $3 \mathrm{~cm}$ from the output of the Ge $x$-ray laser. We then used two multilayer mirrors to image the Al foil in the $x$-ray laser wavelength onto an XUV sensitive CCD (Figure 1). A spherical mirror with a $1 \mathrm{~m}$ radius of curvature was placed $53 \mathrm{~cm}$ from the Al foil, providing a $16 \mathrm{X}$ magnified image of the foil on the CCD at near normal incidence $\left(<0.6^{\circ}\right)$. The CCD was filtered with an additional $0.8 \mu \mathrm{m}$ Al foil to reduce thermal emission from the foil, and a $45^{\circ}$ angle of incidence planar mirror was used to relay the image onto the CCD and spectrally isolate the image from the thermal background noise.

The XUV mirror imaging system used near normal incidence reflection from the spherical imaging mirror to minimize spherical aberrations. The resolution of this imaging system was better than $1 \mu \mathrm{m}$.

We conducted a series of experiments to study the imprinting of a $0.53 \mu \mathrm{m}$ laser beam on a thin Al foil by measuring the modulation

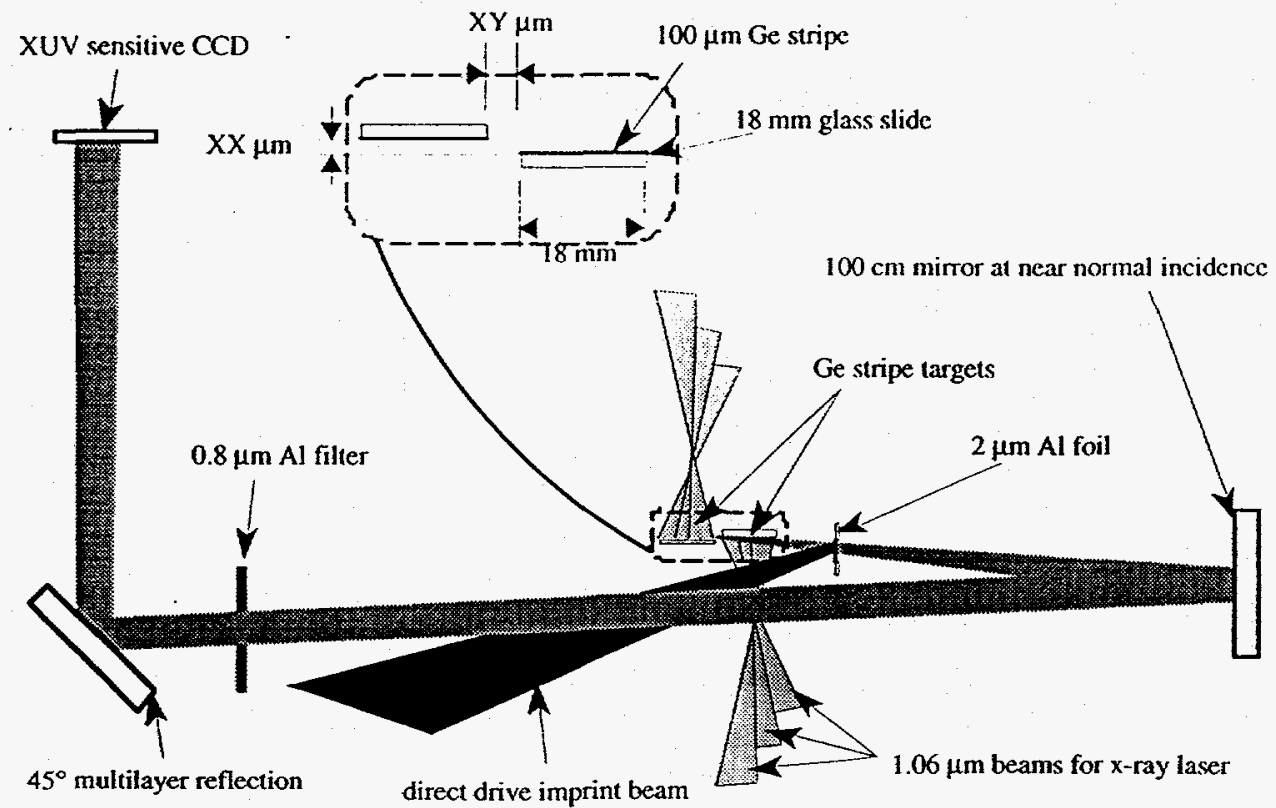

Figure 1: Geometry for the X-ray laser target and XUV imaging system to measure the modulation in optical depth of a thin Al foil due to direct drive laser imprint on Vulcan. 
of the foil as a function of time with various laser smoothing schemes. This modulation was imprinted by variation in optical intensity and enhanced by Rayleigh-Taylor growth at late time.

We used up to two beams of the Vulcan laser as drive beams to directly irradiate the Al foil with the following series of configurations:

\section{Multiple mode laser intensity modulation:}

a) single beam irradiation static speckle pattern

1-I) SSD smoothed speckle pattern ISI smoothed speckle paticm

b) 1 wo bean overlap

slatic speckle pattern

1-D SSI) smoothed sipeckle patten

\section{Single node laser intensity modulation}

a) $15 \mu \mathrm{m}$ wavelength

(1) $30 \mu \mathrm{m}$ waveleneth

In this report. we present preliminary results from the experinents usinge a muliple mole laser infensity umblalation

\section{RESUITSANI) DISCUSSION}

In Figure 2. we show oplical far ficld images of the single beam laser fexal spot recorded duriut these experiments on photographe fim in an equivalese arget plane. This figure shows intensity undulation of a) a satk RPP speckle pattern, b) it

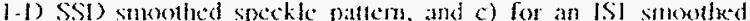
Rlpl' speckle patern. Fach inage shows a 125 mm squate tegion in the focal plane. The stalic sectile patern shoss small siath medulation th intenstly. The iradiatum bean was 1 ? cm in diamketer, with a focal longh of $1 \mathrm{~m}$. The phase plate clencm sige was $07.5 \mathrm{~mm}$. resulting in a minnum speckle size of about 9 fam. The modulation is smovhed with onedimensional streats

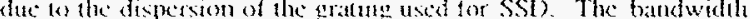

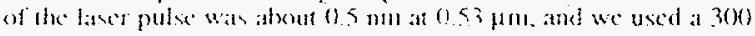

line/mun gating, providing a dispersion of about $0.17 \mathrm{mrad}$. Wo used an RPP with ISI smoothing to generate the smoother irradiation pattern shown in Figure $2 \mathrm{C}$

We irradiated the $2 \mu \mathrm{m}$ thick Al foils direcily by an intensity of $3-$ $8 \times 10^{12} \mathrm{~W} / \mathrm{cm}^{2}$ of $0.53 \mu \mathrm{m}$ laser light using the different speckl pitterns shown above in Figure 2. We recorded the modulation in optical depth in the foil duc to laser imprint and subseqent Rayleigh-Taylor growth using the $G \mathrm{C} x$-ray laser backlighter. We show several XUV radiographs as modulation in optical depth recorded at 02 ns into the laser pulse in Figure 3 for the three cases of imprint due to a static random phase plate (RPP) speckle patten, an speckle pattern smoothed by spectal dispersion (SSI)) and an speckle pattem wh induced spatial incolnerence (ISI smoothing). Power spectra for the imprinted modulation measured in these images are sinown in Figure 4 . These are ploted as power per mode, such that the square root of the inlegral under the curves is the rool mean square (RMS) modulation in the radiograph intage. Note that we also show the

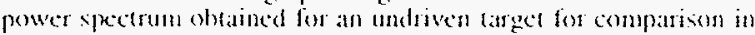
this fivare

The RMS nusulation in optical depth we neasured from the $\lambda$ (IV radiograph shown in fiquas ? were 0.37 . 0.17. and 1920 . The

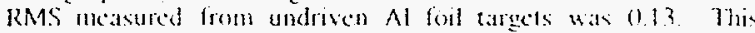

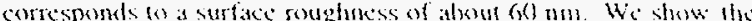
ofpical depth modulation as a function of liane recorded by KlV radiograplyy in Figure 5 . This figure stows that the modulation imprimed due lo a static speckle patem grows faster than for :

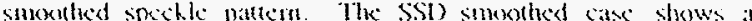

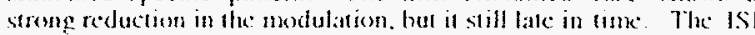
smbotled twath. however, does not show significant groweln at any

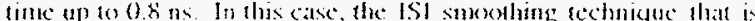
tumplenicated on the Vukan baser introduces a tink skew in the

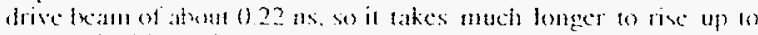

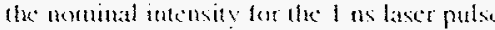

We turther companed the modulation imprinted in the foil dae to overlapping drice beants. We used two beams, both will a 1 is. pulse al 0.53 pm. We onerlapped two beams with at static Rl?

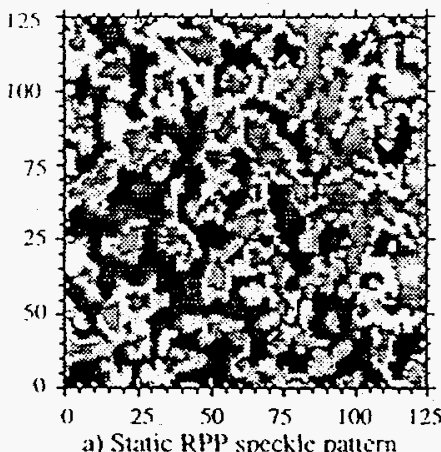

a) Static RPP speckle pattion

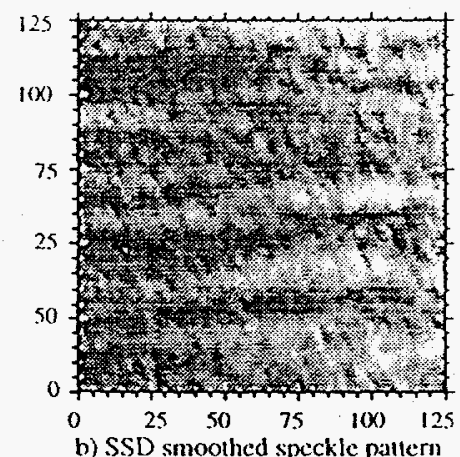

b) SSD smoothed speckle pallern

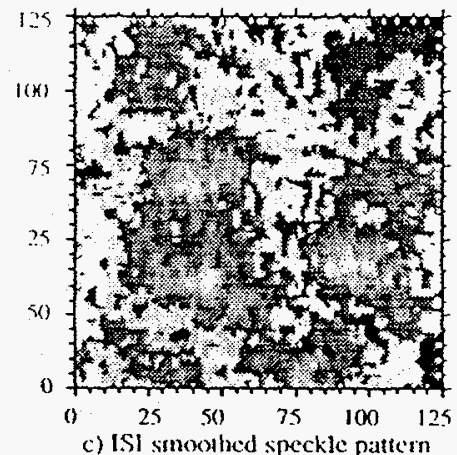

c) ISl smoothed speckle patteon

Figure 2: Equivalent target plane inages of the laser focal spot recorded with a) a static RPp speckle pattem, b) a $l$ dimensional SSD smoothed speckle pattern, and c) an ISI smoothed speckle pattern. The scale is in microns at the target

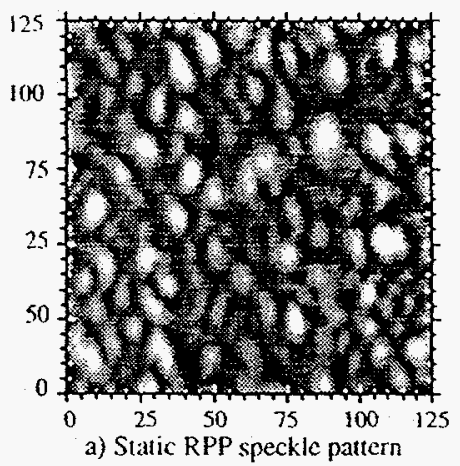

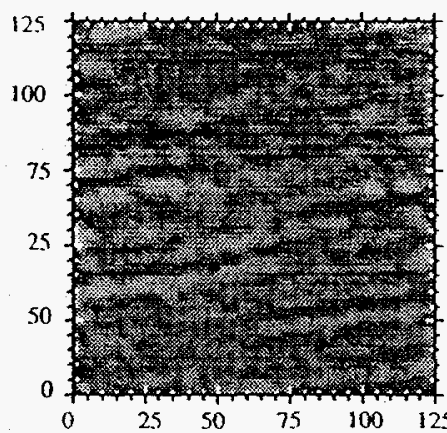

b) SSD smoothed speckle pattern

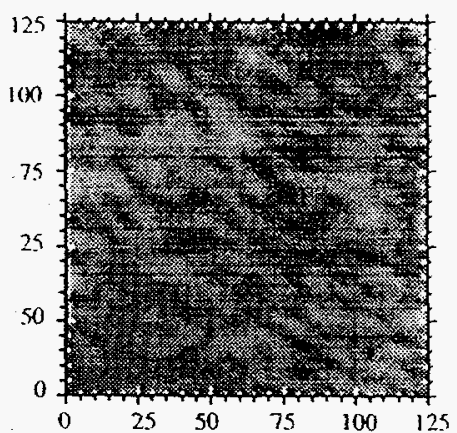

c) ISI smoothed speckle paltern

Figure 3: Modulation in optical depth of an $\mathrm{Al}$ foil irradiated by a $0.53 \mu \mathrm{m}$ direct drive laser beam smoothed with a) a static RPP specklc pattern. b) a 1-dimensional SSD smoothed speckle pattern, and c) an ISI smoothed specklo pattern. These inages were recorded at $200 \mathrm{ps}$ into the drive puise using the Ge $\mathrm{x}$-ray laser backlighter. The scale is in microns at the target, and they are plotted on the same grayscale from -1.2 to +1.2 in optical depth. 


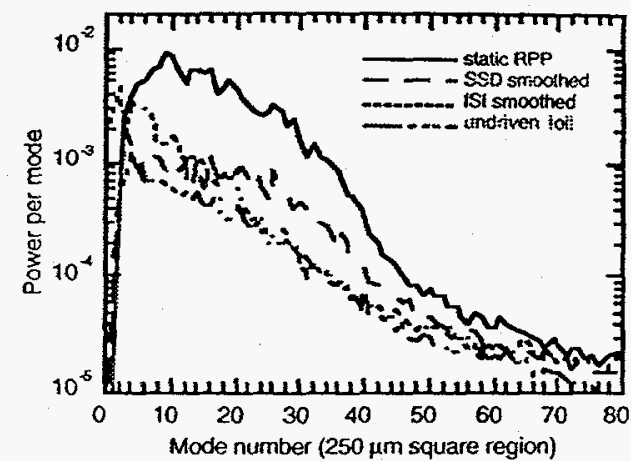

Figure 4: Power per mode caluclated from the XUV optical depth modulation measured from the radiograph images shown in Figure 3.

speckle pattern and two beams with an SSD smoothed speckle pattern.

Figur: 6 shows XUV radiographs recorded at about 0.2 ns for these two cases with an intensity of about $X X$. The equivalent focal plane image for the overlapped static speckle patterns appears to show smaller scale structure than for a single static RPP speckle pattern in Figure 3a. The image for the overlapped SSD smoothed beams shows streaks in two directions because the dispersion direction on the two beams was orthogonal. The RMS modulation in optical depth with two overlapping static speckle pattems was 0.30 . I1 was 0.17 for the two overlapped SSI) smoothed beams.

We also conducted preliminary experiments to compare the imprint and RT growth of single mode vs mulinode nodulations in a thin Al foil. We placed a two-slit aperture in the $0.53 \mu \mathrm{m}$ laser drive beam that provided an Airy pattern to illuminate the target at about $2 \times 10^{13} \mathrm{~W} / \mathrm{cm}^{2}$. The slits were designed to provide and interference pattern with a single dominant wavelength at 1.5 $\mu \mathrm{m}$ and $30 \mu \mathrm{m}$. We recorded a serics of images at different times to measure the growth of the nodulation. Preliminary results from these ancasurements are prescuted separately in this proceedings.

\section{SUMMARY}

These experiments showed that we could make measurments of the modulation imprinted by direct drive on a thin foil using the $G$ $x$-ray laser at the Vulcan laser facility. We made measurements

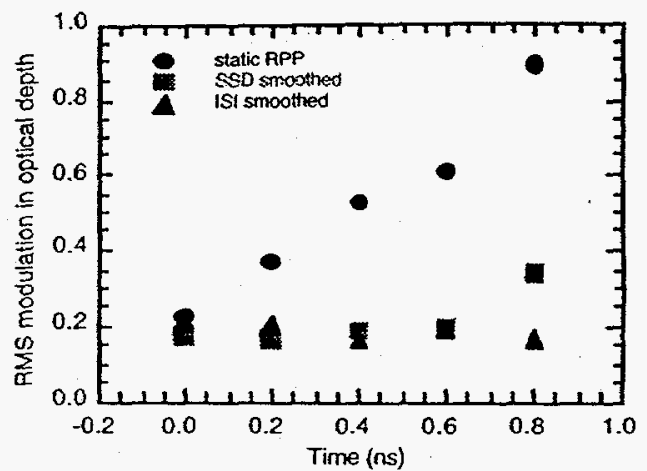

Figure 5: RMS modulation in optical depth of the Al foil measured as a funtion of time for static, SSO smoothed, and ISI smoothed drive beams.

of the imprinted modulation and suhsequent Rayleigh-Taylor growth as a function of lime with various laser smoothing schemes. We also made measurements of the modulation imprinted by a single mode optical perturbation.

Full analysis of the imprint and subsequent Rayleigh-Taylor growth measurements is in progress, and will be reported in full detail in future publications. This will include comparisons of the imprinted modulation with previous experiments made on the Nova laser that used a $0.35 \mu \mathrm{m}$ laser imprint wavelength, as well as with simulations.

\section{REFERENCES}

' M. H. Key. T. W. Barbec. Jr. L. B. DaSilva, S. G. Glendinning. D. H. Kalantar, S. J. Rose, and S. V. Weber, New plasma diagnostic possibilities from radiography with x-ray lasers'. $J$. Quant. Spectrosc. Radiat. Transfer 54. 221 (1995)

2 D. H. Kalanat, T. W. Barbec, Jr, L. B. DaSilva, S. G. Glendinning. M. H. Key, J. P. Knauer, F. Weber, and S. V. Weber, 'X-ray laser radiography of enturbations due to imprint of laser speckle in 0.35 micron laser irradiation of a thin Si foil, Rev. Sci. Insurum. (in press)

3 D. H. Kalantar, M. H. Key, L. B. DaSilva, S. G. Glendinning, J. P. Knaucr B. A Remington, F. Weber, and S. V. Weber. "Measurement of 0.35 micron laser imprint in a thin Si foil using an x-ray laser backlighter, Phys Rev. Lethers (in press)

4 J. Zhang abour the Ge $x$-ray laser

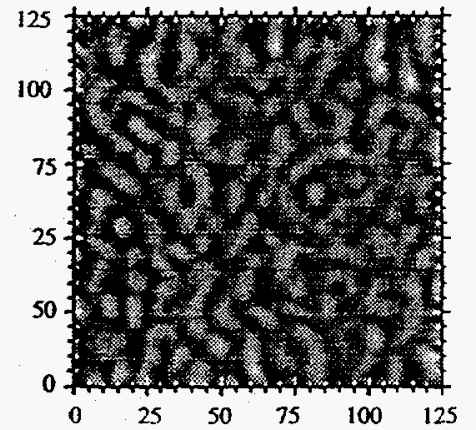

a) Overlapped static RPP speckle pattern

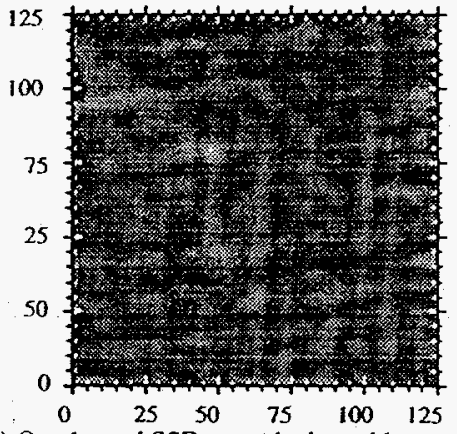

b) Overlapped SSD smoothed speckle patterns

Figure 6: modulation in optical depth of an $\mathrm{Al}$ foil irradiated by two overlapping $0.53 \mu \mathrm{m}$ laser beams with a) static RPP speckle patterns, and b) SSD smoothed speckle patterns.

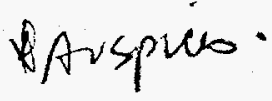

